CASE REPORT

\title{
Nasoenteric tube doppler guided insertion. A case report and review of literature
}

\author{
Sebastián Pablo Chapela $\mathbb{D}^{1,2}{ }^{凶}$, Emiliano Jorge Descotte ${ }^{3}$ and María Jimena Reberendo ${ }^{2}$ \\ (c) The Author(s), under exclusive licence to Springer Nature Limited 2021
}

Nasoenteric tube placement is needed in patients with gastric enteral feeding intolerance or high risk of aspiration. Several techniques are described. Ultrasound is used more commonly for gastric tube placement, but also is described in enteral tube feeding placement. Doppler technique with cold water injection is not described in the literature. We describe a new and easy to realize technique. A case of a 65 years old male patient in the intensive care unit (ICU) with gastroparesis is described. Before beginning a prokinetic drug was administered. In this technique gastric tube placement was bedside assessed with ultrasound, and then the tube was progressed with cold water injection. Duodenal position was confirmed with doppler ultrasound. Ultrasound and doppler technique for nasoenteric tube placement could be a feasible technique to use in the ICU. More studies are needed to assess the effectiveness of the technique.

European Journal of Clinical Nutrition (2022) 76:907-909; https://doi.org/10.1038/s41430-021-01033-x

\section{INTRODUCTION}

Early enteral nutrition is the recommended nutrition therapy when oral intake is not possible in critically ill patients [1, 2]. Also, in patients with gastric feeding intolerance that does not resolve with drugs, post-pyloric feeding is recommended [1, 2]. Delaying the initiation of enteral nutrition is not recommended, because it leads to caloric and protein deficit with its negative consequences [3-8].

Post-pyloric access is not easy [9]. There are several techniques for correct post-pyloric access placement, which includes auscultation, fluoroscopy, endoscopy, self- propelled probes, magnetic devices, and drugs [9, 10]. Ultrasound technique has been described for gastric access [11-15]. There are cases and series of cases describing ultrasound guidance of nasoenteric tube placement, but there is no description of doppler technique for nasoenteric tube placement and confirmation.

This is a case report of a critically ill patient with gastroparesis, and the novel technique of nasoenteric tube placement guided with ultrasound and doppler.

\section{CASE REPORT}

A 65 years old man is referred to our intensive care unit (ICU) service from another center with the diagnosis of meningitis and multiple infectious intercurrences. Nutritional support team is consulted, and enteral nutrition is started.

On the 11th day, the patient continues under mechanical ventilation with propofol and fentanyl infusions and presents vomiting and high gastric residual volume $(550 \mathrm{ml})$. The physical exam presents bowel sounds and depositions. An X-ray is made and a dilated gastric chamber with a nasogastric tube inside is observed (Fig. 1A). The insertion of a nasoenteric tube is decided, and $\mathrm{K}$ K-10 tube for stomach containing drainage is left. Due to the delay of the endoscopic team, the insertion under ultrasound guidance and doppler confirmation is decided.

Before beginning $10 \mathrm{mg}$ of metoclopramide IV was administered. Then, the tube was inserted up to the stomach and confirmed by auscultation. Then, an ultrasound trained intensivist founded the duodenum first with the linear probe and phased array probe (Fig. 2A). After that, for advancing the tube to the duodenum, $20 \mathrm{ml}$ of cold water was given through the tube and this one was advanced $2-4 \mathrm{~cm}$, and the process was repeated until the ultrasound observer found the tube (Fig. 2B). To confirm the position of the tube and continuing advancing a doppler was made which showed the flux in the duodenum (Fig. 2C). Finally, an $X$-ray was made, and it showed the tube in the second part of the duodenum (Fig. 1B).

\section{DISCUSSION}

Post-pyloric nutrition has several indications, like risk of aspiration, gastroparesis among others [1, 2]. Ultrasound is a technique available in the ICU, safe, easy to visualize, with threedimensional spatial view, and with lack of additional cost [16]. Finally, this new tool can offer a new, fast, and safe technique for COVID-19 patients [16, 17]. There are several techniques described for nasoenteric tube placement, including auscultation, fluoroscopy, endoscopy, self-propelled probes, magnetic devices, and drugs $[9,10]$.

Ultrasound technique has already been described for gastric access [11-15]. In a study designed to compare the effectiveness of different methods to verify the nasogastric tube placement in emergency room patients, ultrasonography had $86.4 \%$ of sensitivity and $66.7 \%$ of specificity [15]. In this study it was scanned the oesophagus, the esophagogastric junction, and the fundus and

${ }^{1}$ Facultad de Medicina, Departamento de Bioquímica Humana, Universidad de Buenos Aires, Buenos Aires, Argentina. ${ }^{2}$ Equipo de Soporte Nutricional, Hospital Británico de Buenos Aires, Buenos Aires, Argentina. ${ }^{3}$ Servicio de Terapia Intensiva, Hospital Británico de Buenos Aires, Buenos Aires, Argentina. ${ }^{\circledR}$ email: spchapela@hotmail.com 
A:

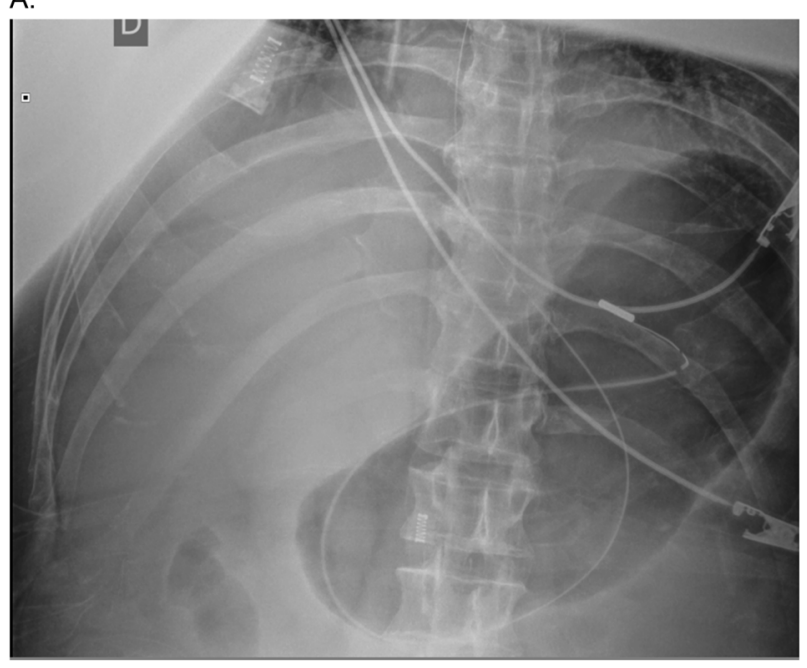

B:

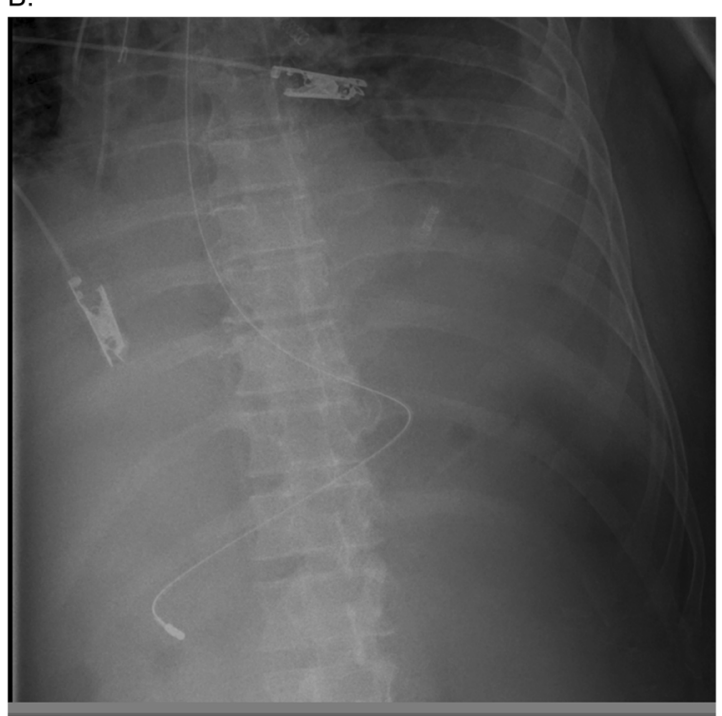

Fig. 1 Abdominal X-ray. A Abdominal X-ray with a dilated gastric chamber, and a nasogastric tube inside. B Abdominal X-ray with nasoenteric tube post-D1 (reaching the second portion of the duodenum).

antrum of the stomach [15]. A similar technique was described by Zatelli and Vezzali for critically ill patients, were sonography of the patient's neck to visualize the esophagus, sonography of epigastrium to confirm the passage through the esophagogastric junction of the tube and the positioning in antrum or fundus, had a sensitivity was $100 \%$ [18]. In another study with patients in the emergency room nasogastric tube localization was verified with neck ultrasound and subxiphoid ultrasound, by giving air-water mixture, and then compared with auscultation, and direct radiography [12]. In this study it was observed that sensitivity of neck ultrasound was $91.5 \%$, and positive predictive value was $100 \%$ and for the subxiphoid ultrasound sensitivity was $78.72 \%$ [12], and when it was combined both scans the sensitivity was even better [12]. In a study with mechanically ventilated patients the visualization of the oesophagus was attempted and the nasogastric tube was inserted under real time visualization of ultrasonography and $92.8 \%$ of the cases the nasogastric tube was observed during the placement within the oesophagus [19]. Similar results were shown in other studies with mechanically
A)

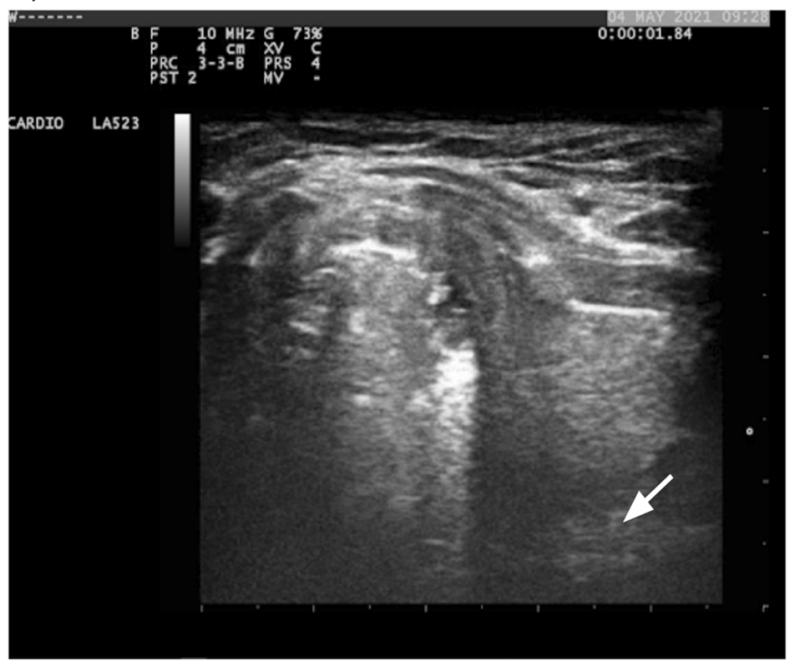

B)

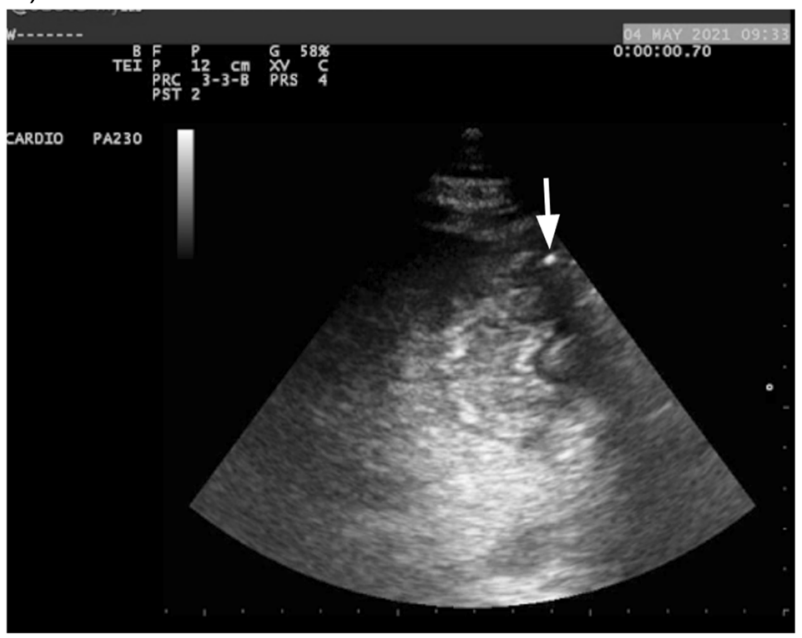

C)

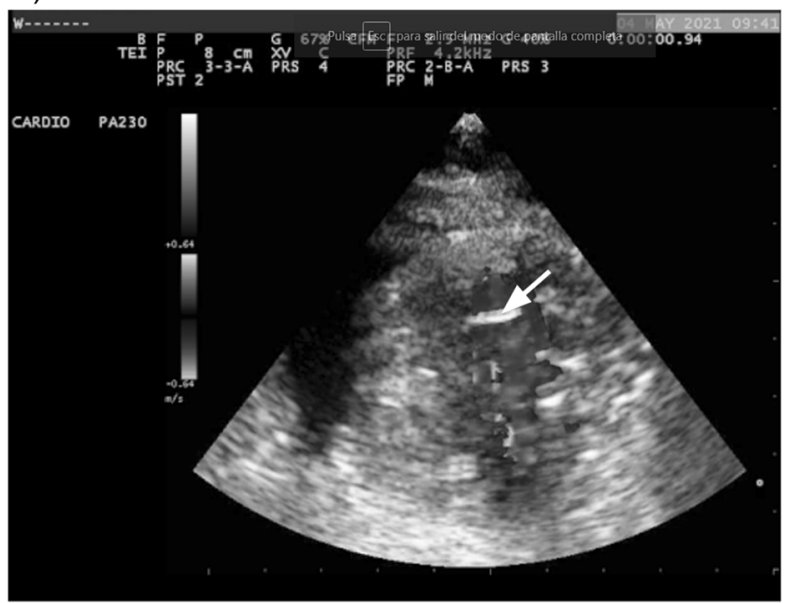

Fig. 2 Abdominal Ultrasound. A Ultrasound transverse view with a linear transducer at the level of the neck (tracheostomy rings in the middle of the image), White arrow shows esophagus with feeding tube inside. B Subcostal view with a phased array probe, transverse to oblique plane showing the gastric antrum and duodenum, white arrow pointing the nasoenteric tube. C Doppler color ultrasound image of antrum and duodenum with nasoenteric tube inside giving $20 \mathrm{ml}$ of cold water confirming tube position. 
ventilated patients where ultrasound technique had a sensitivity of $97 \%[20,21]$. Duodenal placement with ultrasound has been described. Ye et al. described a similar technique than described in the actual paper, but with four points of checking: the cervical esophagus, pylorus, duodenal bulb, and horizontal part of the duodenum [16]. Swartzlander et al. described the placement of a nasoenteric tube in a woman with hyperemesis gravidarum, as X-ray could not be used, via real time sonographic examination was used [22]. Instead of using cold water for doppler technique, air was injected, and the turbulence documented on color Doppler imaging [22].

The potential benefit of this technique is that being a bedside technique there is no need to move the patient to an X-ray room or waiting for the X-ray to confirm the position. Also, the position can be seen in real time, and with an X-ray if the tube is not in position, the tube must be retired and a new tube must be inserted. On the other hand, this technique has some difficulties. First, the equipment disponible is a first line barrier, not all ICU or Internal medicine departments have an ultrasound machine with 7 days a week disponible. Pocus (Point of care ultrasound) is a relatively new skill to learn for the ICU and internal medicine staff and the knowledge spreads slowly [23, 24]. Second: difficulty is that it requires 2 operators, the ultrasound operator and the operator that introduces the tube [25]. Third: ultrasound technique has problems related to the method by itself, gas interposition due to pneumoperitoneum or distended bowel could lead to miss duodenum and stomach or in obese patients the adipose tissue leads to bad image acquisition [25]. Fourth: some patients have injuries on site where they have the ultrasound window, like skin and soft tissue infection with gas on it, burn injuries, or new surgical wounds can mislead an appropriate image acquisition [25]. A potential improve of the technique may be measuring $\mathrm{pH}$ of the material obtained of the tube, this measurement associated with the ultrasound could increase the sensitivity of the technique.

\section{REFERENCES}

1. Singer $P$, Blaser AR, Berger MM, Alhazzani W, Philip C, Casaer $M$, et al. ESPEN guideline on clinical nutrition in the intensive care unit. Clin Nutr. 2018. https:// doi.org/10.1016/j.clnu.2018.08.037

2. Mcclave SA, Taylor BE, Martindale RG, Warren MM, Johnson DR, Braunschweig C, et al. Guidelines for the Provision and Assessment of Nutrition Support Therapy in the Adult Critically III Patient: Society of Critical Care Medicine (SCCM) and American Society for Parenteral and Enteral Nutrition (A.S.P.E.N.). J Parenter Enter Nutr. 2016:40:159-211.

3. Ekpe K, Novara A, Mainardi JL, Fagon JY, Faisy C. Methicillin-resistant Staphylococcus aureus bloodstream infections are associated with a higher energy deficit than other ICU-acquired bacteremia. Intensive Care Med. 2014;40:1878-87.

4. Faisy C, Lerolle N, Dachraoui F, Savard JF, Abboud I, Tadie JM, et al. Impact of energy deficit calculated by a predictive method on outcome in medical patients requiring prolonged acute mechanical ventilation. Br J Nutr. 2009;101:1079-87. https://doi.org/10.1017/S0007114508055669.

5. Faisy C, Llerena MC, Savalle M, Mainardi JL, Fagon JY. Early ICU energy deficit is a risk factor for Staphylococcus aureus ventilator-associated pneumonia. Chest 2011;140:1254-60. https://doi.org/10.1378/chest.11-1499.

6. Villet S, Chiolero RL, Bollmann MD, Revelly JP, Cayeux RN MC, Delarue J, et al. Negative impact of hypocaloric feeding and energy balance on clinical outcome in ICU patients. Clin Nutr. 2005;24:502-9.

7. Compher C, Chittams J, Sammarco T, Nicolo M, Heyland DK. Greater protein and energy intake may be associated with improved mortality in higher risk critically III patients: a multicenter, multinational observational study. Crit Care Med. 2017;45:14-6.
8. Blaser AR, Starkopf J, Alhazzani W, Berger MM, Casaer MP, Deane AM, et al. Early enteral nutrition in critically ill patients: ESICM clinical practice guidelines. Intensive Care Med. 2017;43:380-398.

9. Chen W, Sun $C$, Wei R, Zhang $Y, Y e H$, Chi R, et al. Establishing decision trees for predicting successful postpyloric nasoenteric tube placement in critically III patients. J Parenter Enter Nutr. 2018:42:132-8.

10. Tatsumi H. Enteral tolerance in critically ill patients. J Intensive Care. 2019;7:1-10.

11. Tsujimoto $H$, Tsujimoto $Y$, Nakata $Y$, Akazawa M, Kataoka $Y$. Ultrasonography for confirmation of gastric tube placement. Cochrane Database Syst Rev. 2017;4: CD012083. https://doi.org/10.1002/14651858.CD012083.pub2.

12. Yıldııım Ç, Coşkun S, Gökhan Ş, Pamukçu Günaydın G, Özhasenekler A, Özkula U. Verifying the placement of nasogastric tubes at an emergency center: comparison of ultrasound with chest radiograph. Emerg Med Int. 2018;2018:1-6.

13. Lin T, Gifford W, Lan Y, Qin X, Liu X, Wang J, et al. Diagnostic accuracy of ultrasonography for detecting nasogastric tube (NGT) placement in adults: a systematic review and meta analysis. Int J Nurs Stud. 2017;71:80-8. https://doi. org/10.1016/j.ijnurstu.2017.03.005.

14. Mak MY, Tam G. Ultrasonography for nasogastric tube placement verification: an additional reference. Br J Community Nurs. 2020;25:328-34.

15. Kim HM, So BH, Jeong WJ, Choi SM, Park KN. The effectiveness of ultrasonography in verifying the placement of a nasogastric tube in patients with low consciousness at an emergency center. Scand J Trauma Resusc Emerg Med. 2012;20:1.

16. Ye R, Cheng $X$, Chai $H$, Peng $C$, Liu J, Jing J. A systemic ultrasound positioning protocol for nasointestinal tube in critically ill patients. Crit Care. 2021;25:213.

17. Qian A, Xu S, Lu X, Tang L, Zhang M, Chen X. Rapid positioning of nasogastric tube by ultrasound in COVID-19 patients. Crit Care. 2020;24:1-2.

18. Zatelli M, Vezzali N. 4-Point ultrasonography to confirm the correct position of the nasogastric tube in 114 critically ill patients. J Ultrasound. 2017;20:53-8.

19. Gok F, Kilicaslan A, Yosunkaya A. Ultrasound-guided nasogastric feeding tube placement in critical care patients. Nutr Clin Pract. 2015:30:257-60.

20. Nedel WL, Jost MNF, Filho JWF. A simple and fast ultrasonographic method of detecting enteral feeding tube placement in mechanically ventilated, critically ill patients. J Intensive Care. 2017;5:4-6.

21. Vigneau C, Baudel JL, Guidet B, Offenstadt G, Maury E. Sonography as an alternative to radiography for nasogastric feeding tube location. Intensive Care Med. 2005;31:1570-2.

22. Swartzlander TK, Carlan SJ, Locksmith G, Elms L. Sonographic confirmation of the correct placement of a nasoenteral tube in a woman with hyperemesis gravidarum: case report. J Clin Ultrasound. 2013;41:18-21.

23. Enriquez JL, Wu TS. An introduction to ultrasound equipment and knobology. Crit Care Clin. 2014;30:25-45. https://doi.org/10.1016/j.ccc.2013.08.006.

24. Löwe A, Jenssen C, Hüske S, Zander D, Ignee A, Lim A, et al. "Knobology" in doppler ultrasound. Med Ultrason. 2021;1-7.

25. Mellor TE, Junga Z, Ordway S, Hunter T, Shimeall WT, Krajnik $S$, et al. Not just Hocus POCUS: implementation of a point of care ultrasound curriculum for internal medicine trainees at a large residency program. Mil Med. 2019;184:1-6.

\section{AUTHOR CONTRIBUTIONS}

EJD and SPC performed the technique. MJR and SPC wrote the article.

\section{COMPETING INTERESTS}

EJD and MJR declare no competing interests, and SPC, have received professional fees from Nutricia Argentina and Fresenius-Kabi for advisory boards and lectures.

\section{ADDITIONAL INFORMATION}

Correspondence and requests for materials should be addressed to Sebastián Pablo Chapela.

Reprints and permission information is available at http://www.nature.com/ reprints

Publisher's note Springer Nature remains neutral with regard to jurisdictional claims in published maps and institutional affiliations. 